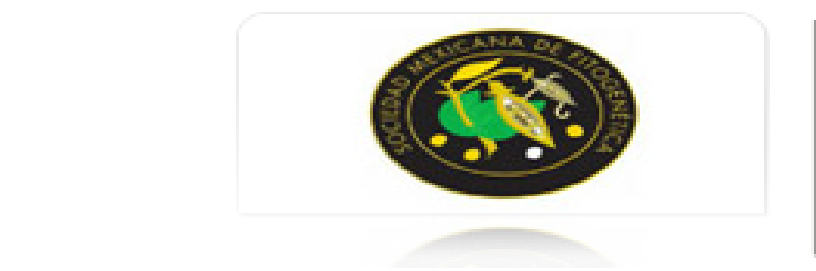

Revista Fitotecnia Mexicana

ISSN: 0187-7380

revfitotecniamex@gmail.com

Sociedad Mexicana de Fitogenética, A.C.

México

Coutiño Estrada, Bulmaro; Salinas Moreno, Yolanda; Gómez Montiel, Noel; Vidal Martínez, Víctor A. 'H-561', NUEVO HÍBRIDO DE MAÍZ RESISTENTE A PUDRICIONES DE MAZORCA PARA REGIONES TROPICALES

Revista Fitotecnia Mexicana, vol. 36, núm. 1, 2013, pp. 85-87

Sociedad Mexicana de Fitogenética, A.C.

Chapingo, México

Disponible en: http://www.redalyc.org/articulo.oa?id=61025678005

Cómo citar el artículo

- Número completo

- Más información del artículo

Página de la revista en redalyc.org

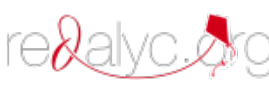

Sistema de Información Científica

Red de Revistas Científicas de América Latina, el Caribe, España y Portugal Proyecto académico sin fines de lucro, desarrollado bajo la iniciativa de acceso abierto 


\section{'H-561', NUEVO HÍBRIDO DE MAÍZ RESISTENTE A PUDRICIONES DE MAZORCA PARA REGIONES TROPICALES}

\section{'H-561', NEW CORN HYBRID EAR ROT RESISTANT FOR TROPICAL REGIONS}

\section{Bulmaro Coutiño Estrada ${ }^{1 \star}$, Yolanda Salinas Moreno $^{2}$, Noel Gómez Montiel $^{3}$ y Víctor A. Vidal Martínez ${ }^{4}$}

\begin{abstract}
${ }^{1}$ Campo Experimental Centro de Chiapas, Instituto Nacional de Investigaciones Forestales, Agrícolas y Pecuarias (INIFAP). km 3 Carr. Ocozocoautla-Cintalapa. 29140, Ocozocoautla, Chiapas. Tel 01(968) 688-2916 al 18 Ext 107. ${ }^{2}$ Laboratorio de Calidad de Maíz, Campo Experimental Valle de México, INIFAP. 56235, Chapingo, Edo. de México. ${ }^{3}$ Campo Experimental Iguala, INIFAP. Iguala, Gro. ${ }^{4}$ Campo Experimental Santiago Ixcuintla, INIFAP. Km 6 entronque Carr. internacional México-Nogales, Apastado Postal 100. Santiago Ixcuintla, Nay.
\end{abstract}

*Autor para correspondencia (coutino.bulmaro@inifap.gob.mx)

En el sureste de México, el Estado de Chiapas es el principal productor de maíz (Zea mays L.) y contribuye con 8.8 $\%$ de la producción nacional (SIAP, 2013). En esa entidad, en el año 2011 se produjeron 1.5 millones de toneladas de grano, en una superficie de 706442 ha, con un rendimiento promedio de $2.2 \mathrm{t} \mathrm{ha}^{-1}$, lo que generó un valor de producción de 6225 millones de pesos. La principal zona maicera de la entidad se encuentra en regiones de clima cálido húmedo y subhúmedo de los Distritos de Desarrollo Rural (DDR) de Tuxtla Gutiérrez, Villaflores, Palenque, Pichucalco, Tapachula, Selva Lacandona y Tonalá, en donde se produce $69 \%$ del grano.

En estas regiones se utilizan semillas mejoradas de variedades de polinización libre y de híbridos, principalmente en los DDR de Tuxtla Gutiérrez y Villaflores, en los cuales el rendimiento promedio es 3.2 y $4.4 \mathrm{t} \mathrm{ha}^{-1}$, respectivamente. Sin embargo, en pruebas de validación de híbridos realizadas por el Instituto Nacional de Investigaciones Forestales, Agrícolas y Pecuarias (INIFAP) en los Distritos de Riego de Chiapas, se ha demostrado que con apoyo de la asistencia técnica y el uso de semilla certificada de los híbridos disponibles en el mercado, los productores pueden obtener más de $7 \mathrm{t} \mathrm{ha}^{-1}$.

En 1999 la industria harinera de Chiapas rechazó 31148 t de grano de maíz producido en Villaflores por presentar daños de pudriciones superiores al máximo aceptable (5\%), y una cantidad menor (no se tienen cifras oficiales) se rechazó en 1998. Ese volumen de grano rechazado por pudriciones equivale a $7 \%$ de la producción de este DDR con un valor de 40.7 millones de pesos (al precio medio rural por tonelada de grano en 1999).
Ante esta situación y a solicitud de productores de maíz y autoridades gubernamentales, durante los años 2000 al 2002 el INIFAP evaluó este tipo de daños en 578 muestras de mazorcas colectadas en todo el estado. Los resultados indicaron que en algunos años y localidades el ataque severo de los hongos de los géneros Diplodia y Fusarium causaban pérdidas de grano de $4.2 \%$ a $19.7 \%$, y que la severidad del daño se relacionaba con los genotipos cultivados, en especial con las variedades criollas (Betanzos et al., 2009).

Por lo anterior, en el Campo Experimental Centro de Chiapas (CECECH) del INIFAP se llevaron a cabo proyectos de hibridación de maíz durante seis años, con el objetivo de obtener híbridos con menores daños de pudriciones de grano causados por estos hongos. Como resultado, se identificó una cruza simple sobresaliente a la que se le denominó 'H-561', la cual presentó mayor rendimiento de grano y menores porcentajes de grano podrido que los híbridos comerciales. El 'H-561' es un híbrido de cruza simple formado por la combinación de las líneas progenitoras Lemoc-1RP (hembra) y Lemoc-2RP (macho), derivadas de las líneas CML-271 y CML-310, respectivamente. Estas dos últimas provenían del CIMMYT; en el CECECH se obtuvieron dos generaciones más de endogamia, en las que se aplicó una selección rigurosa de plantas autofecundadas con menores porcentajes de granos dañados.

La descripción fenotípica de planta y mazorca de las líneas progenitoras y del híbrido 'H-561' se realizó en los años 2007 y 2008, de acuerdo con los descriptores de Carballo y Benítez (2003), y el híbrido se registró en el año 2009 en el Catálogo Nacional de Variedades Vegetales del Servicio Nacional de Inspección y Certificación de Semillas con el número de registro definitivo MAZ-1017-260 210. El porte de planta del 'H-561' varía de $190 \mathrm{~cm}$ a 210 $\mathrm{cm}$, con la mazorca principal insertada de $80 \mathrm{~cm}$ a $85 \mathrm{~cm}$ (Figura 1); la floración media ocurre $60 \mathrm{~d}$ después de la siembra (dds), los estigmas del jilote principal (inflorescencia femenina) son de color verde claro, y las hojas superiores a la mazorca son semierectas de color verde oscuro. Las mazorcas son de $15 \mathrm{~cm}$ a $25 \mathrm{~cm}$ de longitud, de $4 \mathrm{~cm} \mathrm{a}$ $5 \mathrm{~cm}$ de grosor, de forma cónica-cilíndrica, con 12 a 18 hileras, cuyos granos son de textura semidentada y de color blanco cremoso (Figura 2).

La línea Lemoc-1RP tiene una altura de planta de 198 $\mathrm{cm}$, y la de mazorca de $61 \mathrm{~cm}$ a $100 \mathrm{~cm}$; su floración masculina ocurre de 61 a $65 \mathrm{dds}$; los estigmas del jilote (flor femenina) son de color verde claro; las hojas superiores a la mazorca principal son erectas, ligeramente onduladas, de color verde oscuro; las mazorcas miden de 10 a $20 \mathrm{~cm}$ de longitud, son de forma cónico-cilíndrica, con 12 a 16 hileras de grano, de color blanco y textura semidentada y 


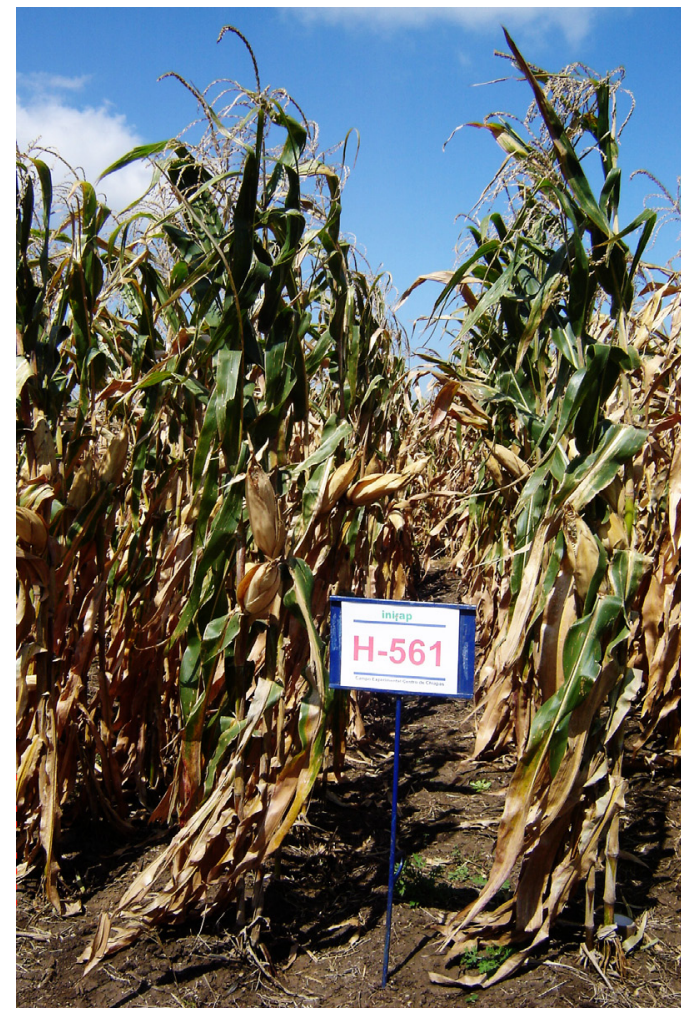

Figura 1. Aspecto de la planta del híbrido 'H-561' en etapa cercana a la cosecha.

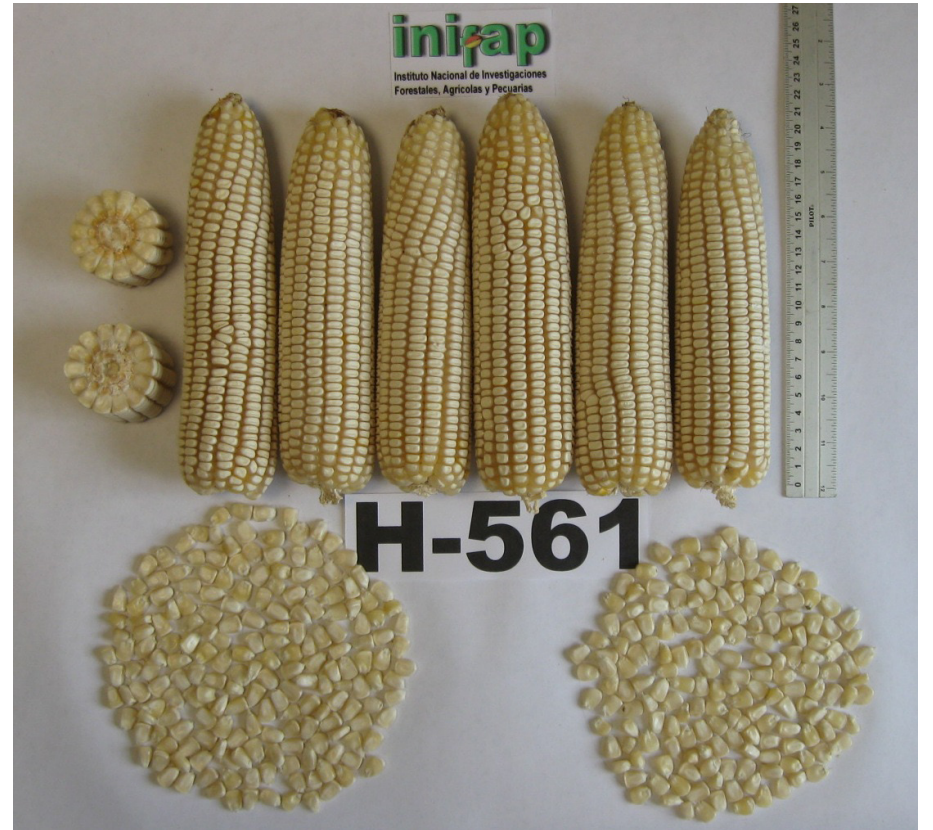

Figura2. Aspecto de mazorca y grano del híbrido de maíz 'H-561' 
semicristalina. De acuerdo con el CIMMYT (1999), esta línea tiene una resistencia ${ }^{1}$ a pudriciones de grano causadas por Diplodia y Helminthosporium de 1.5 y de 1.6, respectivamente. En la línea Lemoc-2RP, las plantas alcanzan hasta $175 \mathrm{~cm}$ de altura; su floración masculina inicia de 56 a 60 dds; sus estigmas son de color verde claro; las hojas superiores son ligeramente curvadas; las mazorcas se insertan de $61 \mathrm{~cm}$ a $100 \mathrm{~cm}$ de altura, son de forma cónica-cilíndrica, de una longitud que varía de $10 \mathrm{~cm}$ a 20 $\mathrm{cm}$, con 12 a 18 hileras de grano, de color blanco cremoso y textura semidentada; esta línea tiene una resistencia de 1.5 a ambas enfermedades.

Las evaluaciones de rendimiento de grano sano y grano podrido, de éste y de otros híbridos experimentales y comerciales se hizo durante una década (de 2001 al 2010) en siembras de secano y de riego, en las principales regiones maiceras de Chiapas y de otras entidades del trópico húmedo y subhúmedo, como Guerrero, Yucatán, Veracruz, Oaxaca y Tamaulipas. La calidad industrial del grano se evaluó en el año 2006.

El 'H-561' es un híbrido muy uniforme, con $15 \%$ a $26 \%$ mayor rendimiento $\left(2.00,0.91\right.$ y $\left.0.53 \mathrm{t} \mathrm{ha}^{-1}\right)$ que los híbridos comerciales 'H-560', 'H-516' y 'P30F94', que se siembran en la región Central de Chiapas. El rendimiento de grano promedio del ' $\mathrm{H}-561$ ' en los ambientes de prueba fue de $7.6 \mathrm{t} \mathrm{ha}^{-1}$, pero en buenas condiciones de humedad produjo hasta $9.8 \mathrm{t} \mathrm{ha}^{-1}$. Una de las cualidades más importantes de este híbrido es su resistencia a las pudriciones de la mazorca causadas por los hongos Diplodia y Fusarium, pues presentó menor porcentaje de granos podridos $(3.7 \%)$ que los híbridos comerciales 'H-560' (14 \%), 'H-516' (7.3\%) y 'P30F94' (12.4 \%).

El grano del ' $\mathrm{H}-561$ ' es de densidad elevada $\left(82.4 \mathrm{~kg} \mathrm{hL}^{-1}\right)$, de tamaño mediano (peso de 100 granos $=38.9 \mathrm{~g}$ ) y uniforme, textura muy dura (índice de flotación $=0 \%$ ), y de color blanco. Estas características lo hacen ideal para la industria de las harinas nixtamalizadas (Salinas et al., 2010), que pro-

$\overline{{ }^{1} \text { En escala de } 1 \text { a } 5 \text {, donde } 1}$ es resistente y 5 es susceptible. duce una tortilla muy blanca (reflectancia a las $2 \mathrm{~h}=95 \%$ ) y suave durante las primeras horas de su elaboración (tortilla caliente), con un rendimiento de masa y de tortilla de $1.8 \mathrm{y}$ $1.5 \mathrm{~kg}$ (por kg de grano), respectivamente.

Para la producción de semilla se recomienda sembrar de cuatro a seis surcos de la línea hembra (Lemoc-1RP), y una semana después sembrar dos surcos de la línea macho (Lemoc-2RP), a una densidad de 40000 plantas por hectárea. Las empresas semilleras o Sociedades de Producción Rural interesadas en adquirir semilla original y registrada de ambas líneas progenitoras, para producir y comercializar semilla certificada, pueden acudir al CECECH.

\section{AGRADECIMIENTOS}

Los autores agradecen a la SAGARPA-CONACYT-COFUPRO el financiamiento del Proyecto 2005-12126 que apoyó parcialmente esta investigación, así como a la participación de Esteban Betanzos Mendoza y Alfonso Ramírez Fonseca, investigadores del INIFAP hasta diciembre del 2007.

\section{BIBLIOGRAFÍA}

Betanzos M E, A Ramírez F, B Coutiño E, N Espinosa P, M Sierra M, A Zambada M, M Grajales S (2009) Híbridos de maíz resistentes a pudrición de mazorca en Chiapas y Veracruz, México. Agric. Tec. Méx. 35:389-398.

Carballo C A, A Benítez R (2003) Manual Gráfico para la Descripción Varietal del Maíz (Zea mays L.). Secretaría de Agricultura, Ganadería, Desarrollo Rural, Pesca y Alimentación (SAGARPA). Servicio Nacional de Inspección y Certificación de Semillas (SNICS). Colegio de Postgraduados. Montecillo, México. 114 p.

CIMMYT, Centro Internacional de Mejoramiento Genético de Maíz y Trigo (1999) Maize Inbred Lines Released by CIMMYT. A Compilation of 424 CIMMYT Maize Lines (CMLs). 1st draft. México, D. F. 56 p.

Salinas M Y, N Gómez M, J Cervantes M, M Sierra M, A Palafox C, E Betanzos M, B Coutiño E (2010) Calidad nixtamalera y tortillera en maíces del trópico húmedo y subhúmedo de México. Rev. Mex. Cien. Agríc. 4:509-523.

SIAP, Servicio de Información y Estadística Agroalimentaria y Pesquera (2013) Anuario Estadístico 2011. SAGARPA. Disponible en: http:/siap.gob.mx (Febrero 2013). 